J. Lake Sci.(湖泊科学), 2009, 21(1): 53-60

http://www.jlakes.org. E-mail: jlakes@niglas.ac.cn

(C2009 by Journal of Lake Sciences

\title{
太湖流域南区湿地磷状况及其滞留能力*
}

\author{
王兆德 ${ }^{1}$, 郑洪福 ${ }^{2}$, 姚菊祥 ${ }^{3}$, 张建英 ${ }^{1}$, 李津津 ${ }^{1}$, 张志剑 ${ }^{* *}$ \\ (1: 浙江大学生态环境研究中心, 杭州 310029) \\ (2: 浙江省杭州市余杭农科所, 杭州 311113) \\ (3: 浙江省气象信息中心, 杭州 310021)
}

摘 要: 选取太湖流域南区 29 个典型湿地采样点进行土-水磷素状况调查, 并采集杭州西湖茅家埠、湖州德清下渚湖、湖州 长兴包漾河等泥样进行静态柱和稳流水槽模拟实验. 研究区域湿地底泥含 TP $0.169-1.200 \mathrm{~g} / \mathrm{kg}$, Olsen-P 7.08-67.08mg/kg, 最 大吸附量为 269.5-824.5mg/kg. NaOH+EDTA-P 占底泥 TP 的 52.0\% $11.6 \%$, 且伴随其积累会提高 Olsen-P 含量. 相应上覆水含 TP $0.036-0.944 \mathrm{mg} / \mathrm{L}$, 总颗粒态磷占 TP 含量的 $70.9 \% \pm 13.2 \%$, DRP 相对较低. 静态柱实验中的 DRP 初始阶段缓慢下降, 之后 快速下降并维持在稳定水平. 稳流水槽实验的 DRP 动态表现出准 U 型曲线特征. 经验证, 底泥的磷素吸附能力在 Langmuir 吸附实验及室内模拟实验中表现一致.

关键词: 湿地; 磷素; 模拟; 准 U 型曲线; 太湖流域

\section{Phosphorus status and retention capacity of wetlands in south region of Taihu Basin China}

\author{
WANG Zhaode ${ }^{1}$, ZHENG Hongfu ${ }^{2}$, YAO Juxiang ${ }^{3}$, ZHANG Jianying ${ }^{1}$, LI Jinjin ${ }^{1} \&$ ZHANG Zhijian ${ }^{1}$ \\ (1: Research Center of Eco-environmental Science, Zhejiang University, Hangzhou 310029, P.R.China) \\ (2: Yuhang Institute of Agricultural Science, Hangzhou 311113, P.R.China) \\ (3: Information Center of Meteorology of Zhejiang Province, Hangzhou 310021, P.R.China)
}

Abstract: The South Lake Taihu region is increasingly threatened by water eutrophication, so it is important to understand phosphorus status in sediments and water of the riparian wetlands in this region and develop sound technologies for optimizing wetlands' ecological values. 29 typical sampling sites in this region were chosen for the investigation, and the sites located at Hangzhou West Lake, Deqing Xiazhuohu Wetland, and Changxing Baoyanghe River were selected for static column simulation experiments and steady-flow flume simulation experiments. According to the investigation, total phosphorus (TP) and $\mathrm{NaHCO}_{3}$ $(\mathrm{pH}=8.5)$ extractable phosphorus (Olsen-P) in sediments of the region reached $0.169-1.200 \mathrm{~g} / \mathrm{kg}$ and $7.08-67.08 \mathrm{mg} / \mathrm{kg}, \mathrm{respecially}$, and the adsorption capacity $\left(Q_{\max }\right)$ of sediments varied from 269.5 to $824.5 \mathrm{mg} / \mathrm{kg}$. NaOH+EDTA extractable phosphorus (NaOH+EDTA-P) constituted $52.0 \% \pm 11.6 \%$ of TP, while Olsen-P was increased as organic phosphorus accumulated. TP in overlying water was $0.036-0.944 \mathrm{mg} / \mathrm{L}$, while dissolved reactive phosphorus (DRP) was relatively and $34.5 \%$ of the total sites was below detective limits. Total particle phosphorus (TPP) contributed $70.9 \% \pm 13.2 \%$ of TP in water samples. There was no significant relationship between TP, DRP in overlying water and TP, NaOH+EDTA-P, Olsen-P in sediments, implying that phosphorus status in sediments was not the only factor restricting phosphorus in overlying water. In the static column simulation experiments, DRP in overlying water decreased slowly at the beginning, then decreased fastly later on. A quasi U-pattern curve was found in the steady-flow flume simulation experiments, i.e. DRP in the overlying water decreased at first and then turned to be increasing. It indicated that the role of the sediments might be changed from phosphorus "sink" to "source" when high phosphorus water flow over

* 国家自然科学基金(40701162)和浙江省自然科学基金(Y506215)联合资助. 2008-01-21 收稿; 2008-02-25 收修改稿. 王兆 德, 男, 1983 年生, 硕士研究生; E-mail: wzd2011@163.com.

** 通讯作者; E-mail: zhangzhijian@zju.edu.cn. 
a wetland in rain season. It was also proved in the simulation experiments that organic matter accelerated the adsorption rates of phosphorus by sediments.

Keywords: Wetland; phosphorus; simulation; quasi U-pattern curve; Taihu Basin

21 世纪初, 中国水污染的核心问题之一是水体富营养化. 太湖流域南区是太湖流域水体富营养化控 制的关键区块之一, 然而问题仍十分突出 ${ }^{[1]}$, 其核心问题仍然是氮、磷等生源要素过剩及由此而产生的藻 类大量增殖、溶解氧减少、透明度下降与水体生态功能恶化. 在一定条件下, 湿地可在生源要素人湖之 前综合物理吸附作用、水生动植物作用、微生物作用、化学沉降作用等多途径复杂过程对其进行有效 截留. 湿地磷素生态截留功能最大化的研究与实践是目前国内外面源污染控制首选的生态控制途径之 - ${ }^{[2-4]}$. 磷元素是各种生态系统中的重要限制因子, 尤其在湿地中, 磷元素的限制作用显著强于氮元素 ${ }^{[5]}$, 这使得湿地中磷元素的循环转化机理成为当今水环境研究领域的一大重点.

然而, 利用湿地的磷素调节与管理过程如果违反了湿地自身的基本规律, 将有可能导致整个生态系 统发生不可逆转的变化 ${ }^{[6-7]}$. 经过多年的努力, 外源性污染已得到有效遏制和削减, 继而内源性污染的重 要性却日益凸显 ${ }^{[8]}$. Jeppesen 等综合全球不同纬度和海拔, 并且水深及营养状态各异的 35 个湖泊的长期 研究成果, 指出在外源输人削减后, 大多数湖泊中的总磷浓度要经历 10-15 年才可达到新的平衡, 影响 恢复力的最主要因素是内源负荷 ${ }^{[9]}$. 浅水湖泊(湿地)底泥磷库一般比上覆水高出 100 倍以上, 外源削减后 上覆水浓度显著地受制于泥-水界面的反应 ${ }^{[8]}$. 大量针对湖泊、湿地、河道等的研究显示, 底泥在对磷 元素的吸附-解吸动态过程中存在一阈值点, 即底泥磷素 “汇-源” 转换阈值, 若越过此阈值点则解吸 过程会占据优势, 使底泥成为重要的内污染源 ${ }^{[10-12]}$, 这也与生态系统的多稳态阈值理论相符合 ${ }^{[13-14]}$. 开展底泥磷元素的 “汇-源” 转化规律研究, 可为优化湿地磷素截留功能最大化提供理论支撑, 服务于 浅水湖泊外源性营养盐的控制; 同时，也可作为浅水湖泊内源性营养盐控制的重要理论参考. 对于底 泥磷素 “汇-源” 转换阈值, 普遍基于线性模型、Langmuir 模型、对数模型等理论, 并结合吸附实验进 行探究 ${ }^{[10-12]}$. 然而, 通过对我国湿地底泥吸附一解吸过程的适地条件模拟来研究 “汇-源” 转换规律的 报道相对较少.

本研究通过对太湖流域南区典型湿地的底泥、上覆水的普查, 揭示现阶段太湖流域南区湿地的磷素 状况，以评价湿地底泥的磷素截流潜能及释放风险。通过室内静态柱模拟实验和稳流水槽模拟实验，研 究湿地底泥吸附上覆水磷素的动态过程及影响因素, 同时进行底泥磷素 “汇-源” 转换规律的浅析.

\section{1 材料和方法}

\section{1 底泥、上覆水样品采集}

太湖流域南区特指太湖流域浙江区，位于浙江省北部，面积 $12093 \mathrm{~km}^{2}$ ，占整个太湖流域的 $32.8 \%$, 北 与太湖相接, 境内主要河流西芳溪、东苕溪及东部水网的部分水体均流人太湖, 对太湖湖体营养状态的 水平具有至关重要的影响. 该区域河网、湖泊密布, 天然及次生湿地类型广泛, 数量众多, 也是浙江省农 业磷素面源污染最为严重的地区 ${ }^{[15]}$. 本研究在太湖流域南区的农业区 $(\mathrm{A}) 、$ 居民区 $(\mathrm{L})$ 、养殖区 $(\mathrm{F}) 、$ 旅游 区 $(\mathrm{R}) 、$ 水源区 $(\mathrm{D})$ 区及综合区 $(\mathrm{C})$ 等代表性区块内, 选取具有富营养化等级差异明显的天然或次生湿地 29 处(图 1)进行调查采样. 经篮选, 确定杭州西湖茅家埠(R2)、湖州德清下渚湖湿地(R7)、湖州长兴包漾河 (D1)三处批量采集底泥样品带回实验室进行模拟实验研究. 于 2007 年 4-5 月于各采样点利用 PVC 柱状 采样器采取 0-10cm 表层底泥, 同时采集相应的上覆水样. 底泥样品置于阴凉通风处自然风干后过篮, 密 封避光保存待分析.

\section{2 理化分析}

1.2.1 底泥样品 (1)总磷(TP): 过 100 目泥样采用 $\mathrm{HClO}_{4}-\mathrm{H}_{2} \mathrm{SO}_{4}$ 消化-钿锑抗分光光度法测定; (2) $\mathrm{NaHCO}_{3}$ 浸提磷(Olsen-P): 过 20 目泥样用 $0.5 \mathrm{~mol} / \mathrm{L} \mathrm{NaHCO}_{3}(\mathrm{pH}=8.5)$ 以水土比 $20: 1$ 振荡平衡 $0.5 \mathrm{~h}$, 分析滤液中的 磷含量 ${ }^{[16]}$. (3) NaOH+EDTA 浸提磷 $(\mathrm{NaOH}+\mathrm{EDTA}-\mathrm{P})$ : 过 20 目泥样用 $0.5 \mathrm{~mol} / \mathrm{L} \mathrm{NaOH}+0.1 \mathrm{~mol} / \mathrm{L}$ EDTA(1:1) 以水土比 $20: 1$ 振荡平衡 $16 \mathrm{~h}$, 滤液用 $\mathrm{K}_{2} \mathrm{~S}_{2} \mathrm{O}_{8}$ 消化-钼锑抗分光光度法测定磷含量 ${ }^{[17]}$. (4)有机质: 过 100 
目泥样采用 $\mathrm{K}_{2} \mathrm{Cr}_{2} \mathrm{O}_{7}$ 容量法-外加热法测定 ${ }^{[16]}$. 5磷素吸附容量：水土比 $20: 1$, 加人含磷 0-50mg/L 的 $\mathrm{KH}_{2} \mathrm{PO}_{4}$ 溶液, $25^{\circ} \mathrm{C}$ 恒温振荡 $24 \mathrm{~h}$, 绘制 Langmuir 等温吸附曲线, 求得最大磷素吸附容量 $Q_{\max }$ 和系数 $k$.

1.2.2 上覆水样品 部分水样经 $0.45 \mu \mathrm{m}$ 滤膜过滤制得过滤水样. $\mathrm{pH}$ : 利用 PHS- $25 \mathrm{C}$ 酸度计进行测定; 总氮 $(\mathrm{TN})$ : 未滤水样通过 $\mathrm{K}_{2} \mathrm{~S}_{2} \mathrm{O}_{8}$ 消化一紫外分光光度法测定; TP: 未滤水样通过 $\mathrm{K}_{2} \mathrm{~S}_{2} \mathrm{O}_{8}$ 消化-钼锑抗分光光度 法测定; 溶解态活性磷(DRP): 过滤水样直接通过钼锑抗分光光度法测 定 $^{[18]}$. 总溶解磷(TDP): 过滤水样 通过 $\mathrm{K}_{2} \mathrm{~S}_{2} \mathrm{O}_{8}$ 消化-钼锑抗分光光度法测定. 总颗粒态磷 (TPP)为 TP 与 TDP 之差. 溶解态有机磷(DOP)为 TDP 与 DRP 之差 ${ }^{[19]}$.

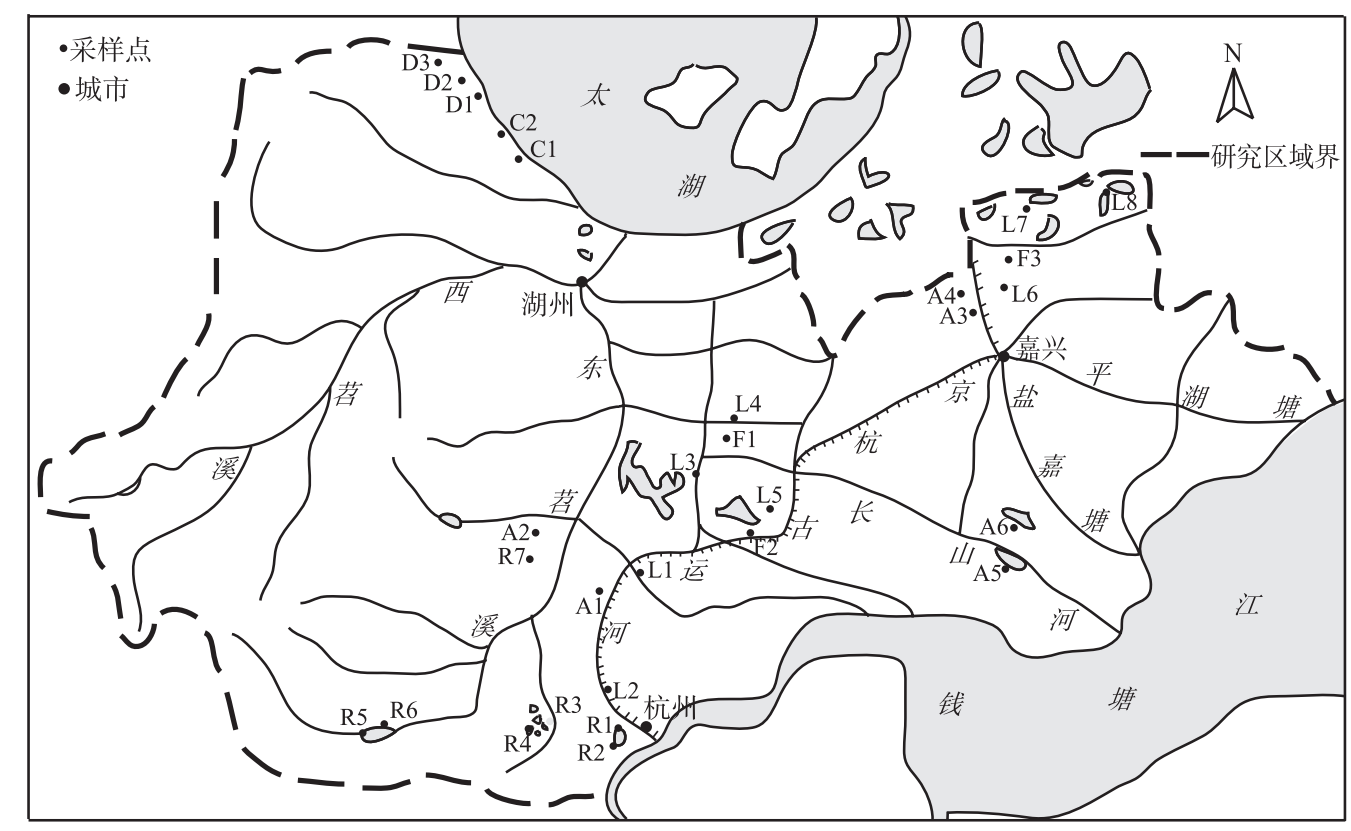

图 1 太湖流域南区湿地采样点

Fig.1 Sampling locations of the investigated wetland in south region of Taihu Basin

\section{3 室内模拟实验}

1.3.1 静态柱模拟实验 选取 R2、D1、R7 三处样品分别进行一组静态柱模拟实验. 每组实验预制一系列 内径 $12 \mathrm{~cm}$ 、高 $50 \mathrm{~cm}$ 、下端封口的 PVC 柱状容器. 配置浓度系列为 $0 、 0.5 、 1.0 、 2.0 、 4.0 、 7.0 、 10.5 \mathrm{mg} / \mathrm{L}$ 的 $\mathrm{KH}_{2} \mathrm{PO}_{4}$ 溶液. 每一实验柱底部加人等量新鲜底泥至 $5 \mathrm{~cm}$ 深, 将不同磷浓度的系列溶液各 $1.36 \mathrm{~L}$ 不扰动 表层底泥地缓慢依次注人 7 个盛有新鲜底泥的实验柱中，灌注至水深 $40 \mathrm{~cm}$. 盖住柱口并留通气孔，移至 $25^{\circ} \mathrm{C}$ 恒温室，避光静止培养. 第 $1 、 3 、 7 、 14 、 21 、 28 、 35 \mathrm{~d}$ 于平均水深处采取适量上覆水样，随即分析 水样 DRP 浓度. 每次取样之前用蒸馏水补充上覆水至原水深, 以补充上覆水的蒸发损失; 每次采样并分 析 DRP 之后, 以相同 DRP 浓度的溶液补充上覆水至原刻度.

1.3.2 稳流水槽模拟实验 选取 R2、D1、R7 三处样品分别进行一组稳流水槽模拟实验. 每组实验分别预 制 4 个长 $50 \mathrm{~cm}$ 、宽 $30 \mathrm{~cm}$ 、高 $30 \mathrm{~cm}$ 、上端开口的长方体玻璃水槽，内设两层挡板使水流成 $\mathrm{S}$ 流形以延长 水力停留时间 $(H R T)$, 容器设进、出水孔. 配置浓度系列为 $0 、 1.0 、 2.0 、 5.0 \mathrm{mg} / \mathrm{L}$ 的 $\mathrm{KH}_{2} \mathrm{PO}_{4}$ 溶液. 实验 前每一容器加人等量新鲜底泥至 $5 \mathrm{~cm}$ 深, 将不同磷浓度的系列溶液不扰动表层底泥地缓慢依次注人 4 个 盛有新鲜底泥的水槽中, 灌注至水深 $20 \mathrm{~cm}$ (恰好至出水口). 同时调节高处的水箱流速开始向容器输送相 应浓度的 $\mathrm{KH}_{2} \mathrm{PO}_{4}$ 溶液, 并打开出水孔自流排水, 控制 $\mathrm{HRT}=2 \mathrm{~d}$ (流速 $v=0.45 \mathrm{~m} / \mathrm{s}$ ) 于室温下进行稳流实验. 于第 $1 、 3 、 7 、 14 、 21 、 28 、 35 \mathrm{~d}$ 采取适量上覆水样，随即分析水样 DRP 浓度. 


\section{2 结果与讨论}

\section{1 太湖流域南区湿地底泥与上覆水磷素状况}

2.1.1 湿地底泥磷素状况 调查期间太湖流域南区 29 处湿地采样点的底泥磷素状况统计见表 1. 该区域内 $\mathrm{TP}$ 含量范围为 $0.17-1.200 \mathrm{~g} / \mathrm{kg}$, 最低值是杭州西溪湿地的秋雪庵采样点(R3), 该采样点为国家重点保护 的天然湿地, 受到人类活动污染较轻; 最高值出现在嘉兴连泗荡 (F3), 这主要是由该地农户在水体 内进行大规模水产养殖产生的大量有机碎屑沉积所致. 研究区域内 Olsen-P 含量在 7.08-67.08mg/kg 之间, 含量峰值出现在嘉兴嘉善北港(L8), 当环境处于厌氧条件下极易释放磷素到上覆水层 ${ }^{[20]}$. 该 区域湿地底泥最大磷素吸附容量最低为 $269.5 \mathrm{mg} / \mathrm{kg}$, 最高为 $824.5 \mathrm{mg} / \mathrm{kg}$, 平均 $497.2 \pm 132.9 \mathrm{mg} / \mathrm{kg}$, 与 相同区域水稻土的吸附容量相当 ${ }^{[21]}$, 物理吸附能力较弱. 同时, $64.5 \%$ 的采样点 $Q_{\max }$ 小于 TP, 说明大 多数湿地底泥物理吸附能力已趋饱和, 同时也发生着相对缓慢的化学及物理化学吸附 ${ }^{[22]}$, 磷素物理 吸附潜力较低.

\section{表 1 太湖流域南区湿地底泥理化指标 ${ }^{*}$}

Tab.1 Physi-chemical characteristics of wetland sediments in south region of Taihu basin

\begin{tabular}{|c|c|c|c|c|c|c|c|}
\hline \multicolumn{2}{|l|}{ 指标 } & \multirow{2}{*}{$\begin{array}{c}\text { 农业区 } \\
21.61 \pm 10.70\end{array}$} & \multirow{2}{*}{$\begin{array}{c}\text { 养殖区 } \\
42.21 \pm 36.45\end{array}$} & \multirow{2}{*}{$\begin{array}{c}\text { 居民区 } \\
38.55 \pm 12.35\end{array}$} & \multirow{2}{*}{$\begin{array}{c}\text { 旅游区 } \\
80.71 \pm 104.85\end{array}$} & \multirow{2}{*}{$\begin{array}{c}\text { 水源区 } \\
27.91 \pm 11.33\end{array}$} & \multirow{2}{*}{$\begin{array}{c}\text { 综合区 } \\
27.91 \pm 26.74\end{array}$} \\
\hline 有机质 & 均值 & & & & & & \\
\hline & 范围 & $12.91-40.40$ & $17.67-94.09$ & $20.64-60.60$ & $15.92-310.23$ & $18.41-40.45$ & $9.00-46.82$ \\
\hline $\mathrm{TP}$ & 均值 & $0.559 \pm 0.149$ & $0.783 \pm 0.363$ & $0.516 \pm 0.198$ & $0.566 \pm 0.233$ & $0.580 \pm 0.279$ & $0.315 \pm 0.202$ \\
\hline & 范围 & $0.307-0.755$ & $0.533-1.200$ & $0.245-0.843$ & $0.169-0.919$ & $0.293-0.851$ & $0.172-0.457$ \\
\hline \multirow[t]{2}{*}{$\mathrm{NaOH}+\mathrm{EDTA}-\mathrm{P}$} & 均值 & $268.4 \pm 34.4$ & $473.9 \pm 223.2$ & $266.3 \pm 123.4$ & $335.9 \pm 146.8$ & $213.5 \pm 70.2$ & $128.6 \pm 76.2$ \\
\hline & 范围 & $176.9-397.3$ & $288.1-721.2$ & $134.6-467.0$ & $103.6-587.5$ & $145.9-286.0$ & $74.7-182.5$ \\
\hline \multirow[t]{2}{*}{ Olsen-P } & 均值 & $30.29 \pm 9.37$ & $45.39 \pm 19.59$ & $26.97 \pm 18.88$ & $26.84 \pm 8.24$ & $23.04 \pm 5.07$ & $10.60 \pm 4.98$ \\
\hline & 范围 & $18.06-45.53$ & $22.85-58.35$ & $11.59-67.08$ & $13.84-38.63$ & $18.06-28.21$ & $7.08-14.12$ \\
\hline \multirow[t]{2}{*}{$Q_{\max }$} & 均值 & $547.4 \pm 198.2$ & $493.5 \pm 87.0$ & $512.0 \pm 100.1$ & $443.1 \pm 107.3$ & $564.3 \pm 164.0$ & $381.4 \pm 111.2$ \\
\hline & 范围 & $389.2-824.5$ & $411.9-585.0$ & $354.6-692.9$ & $269.5-587.9$ & $415.2-740.0$ & $302.8-460.0$ \\
\hline
\end{tabular}

* 单位: 有机质、 $\mathrm{TP}$ 为 $\mathrm{g} / \mathrm{kg}$; 其它指标为 $\mathrm{mg} / \mathrm{kg}$.

将底泥重要磷素指标做相关分析发现，底泥 TP、Olsen-P 均与 NaOH+EDTA-P 具有显著的线性相关 关系 $\left(R^{2}\right.$ 分别为 $\left.0.7409,0.6005\right)$. 经分析, $\mathrm{NaOH}+\mathrm{EDTA}-\mathrm{P}$ 占 TP 含量达 $52.0 \% \pm 11.6 \%$, 由于 $\mathrm{NaOH}+\mathrm{EDTA}-\mathrm{P}$ 代表底泥中有机磷含量的高低 ${ }^{[17]}$, 可以推断, 太湖流域南区湿地底泥中的有机磷在 TP 含量中占有相对 稳定的比例. 底泥有机磷积累的同时, Olsen-P 的含量也相应提高, 磷素释放风险随之加大, 这与有关研 究者发现有机磷肥可提高水田磷素流失风险相一致 ${ }^{[23]}$. 关于有机磷引起 Olsen-P 增加的原因是多元的, 有机磷的增加会加剧底泥中大量微生物的降解活动而产生更多的活性磷酸盐 ${ }^{[24]}$, 随有机磷带人的大分子 有机质可竞争性地吸附磷酸盐而暂时抑制其向水相释放的过程 ${ }^{[25]}$, 有机磷长时间的矿化过程也会源源不 断产生大量活性磷酸盐 ${ }^{[26]}$. 因此，虽然有机磷活性较低，却是底泥磷素释放的潜在源，在湿地及浅水湖 泊的内源污染控制中不可忽视其重要性.

2.1 .2 湿地上覆水磷素状况 太湖流域南区 29 处采样点湿地的上覆水磷素含量(表 2)说明, 该区域上覆 水 $\mathrm{TP}$ 含量为 $0.036-0.944 \mathrm{mg} / \mathrm{L}$, 最低值是受到人类活动污染较轻的杭州西溪湿地百家楼采样点 $(\mathrm{R} 4)$, 最高值出现在富营养化异常严重的太湖采样点(北)(C2). 研究区域内 DRP 含量普遍较低, $31.3 \%$ 的水 体低于检测限范围，指标最高值出现在嘉兴连泗荡(F3), 该点也是底泥 TP 含量最高的点位. 各采样 点 DRP 和 DOP 含量相对较低, 而 TPP 占到了 TP 含量的 70.9\% $13.2 \%$. 这说明, 4-5 月份在所调查的 范围内, 磷在上覆水中的含量主要以颗粒形态存在. Selig 等对德国具有富营养化特征的 Bützow 湖的 
调查同样显示, TPP 含量百分比在 5 月份达到一年中的最大值 $70 \%{ }^{[27]}$. 除了风力等自然扰动外，其它 非自然因素诸如航运、渔业操作、农业灌排等都可以引起湿地底部沉积磷的再悬浮，导致颗粒态磷 含量较高.

表 2 太湖流域南区湿地上覆水理化指标 ${ }^{*}$

Tab.2 Physi-chemical characteristics of overlying water of wetlands in south region of Taihu basin

\begin{tabular}{cccccccc}
\hline \multicolumn{2}{c}{ 指标 } & 农业区 & 养殖区 & 居民区 & 旅游区 & 水源区 & 综合区 \\
\hline \multirow{2}{*}{$\mathrm{pH}$} & 均值 & $7.51 \pm 0.30$ & $7.51 \pm 0.27$ & $7.57 \pm 0.27$ & $7.65 \pm 0.21$ & $7.36 \pm 0.15$ & $7.82 \pm 0.22$ \\
& 范围 & $7.22-7.89$ & $7.28-7.80$ & $7.26-7.92$ & $7.31-7.93$ & $7.21-7.50$ & $7.66-7.97$ \\
$\mathrm{TP}$ & 均值 & $0.239 \pm 0.077$ & $0.219 \pm 0.164$ & $0.257 \pm 0.119$ & $0.089 \pm 0.031$ & $0.130 \pm 0.040$ & $0.821 \pm 0.174$ \\
& 范围 & $0.121-0.332$ & $0.071-0.395$ & $0.128-0.445$ & $0.036-0.128$ & $0.085-0.163$ & $0.698-0.944$ \\
$\mathrm{NRP}$ & 均值 & $0.031 \pm 0.040$ & $0.053 \pm 0.077$ & $0.032 \pm 0.024$ & $0.008 \pm 0.010$ & $0.019 \pm 0.002$ & $0.016 \pm 0.023$ \\
& 范围 & $\mathrm{ND}-0.106$ & $\mathrm{ND}-0.141$ & $\mathrm{ND}-0.071$ & $\mathrm{ND}-0.022$ & $0.018-0.022$ & $\mathrm{ND}-0.032$ \\
$\mathrm{TDP}$ & 均值 & $0.075 \pm 0.040$ & $0.091 \pm 0.074$ & $0.066 \pm 0.040$ & $0.027 \pm 0.008$ & $0.038 \pm 0.016$ & $0.043 \pm 0.010$ \\
& 范围 & $0.025-0.134$ & $0.018-0.166$ & $0.025-0.148$ & $0.018-0.039$ & $0.029-0.057$ & $0.036-0.050$ \\
$\mathrm{TPP}$ & 均值 & $0.164 \pm 0.055$ & $0.128 \pm 0.091$ & $0.191 \pm 0.096$ & $0.063 \pm 0.030$ & $0.092 \pm 0.039$ & $0.778 \pm 0.164$ \\
& 范围 & $0.078-0.222$ & $0.053-0.229$ & $0.103-0.353$ & $0.015-0.103$ & $0.057-0.134$ & $0.662-0.894$ \\
$\mathrm{NOP}$ & 均值 & $0.041 \pm 0.032$ & $0.034 \pm 0.032$ & $0.031 \pm 0.029$ & $0.012 \pm 0.005$ & $0.019 \pm 0.014$ & $0.022 \pm 0.025$ \\
& 范围 & $0.014-0.085$ & $0.007-0.070$ & $0.011-0.099$ & $0.004-0.018$ & $0.011-0.035$ & $0.004-0.039$ \\
\multirow{2}{*}{$\mathrm{TN}$} & 均值 & $2.566 \pm 1.091$ & $3.125 \pm 1.663$ & $2.031 \pm 1.153$ & $3.438 \pm 1.982$ & $2.177 \pm 0.759$ & $10.027 \pm 1.861$ \\
& 范围 & $1.367-4.516$ & $0.390-4.704$ & $0.979-4.516$ & $0.885-6.126$ & $1.484-2.988$ & $8.711-11.343$ \\
\hline \multirow{2}{*}{$\mathrm{ND}:$} & 检出
\end{tabular}

* ND: 未检出; 除 $\mathrm{pH}$ 外, 其它单位均为 $\mathrm{mg} / \mathrm{L}$.

2.1.3 湿地底泥、上覆水磷素含量的相关性 将全部湿地采样点底泥各形态磷含量与对应的上覆水 TP、 DRP 含量进行回归分析. 发现上覆水 TP、DRP 与底泥中的 TP、NaOH+EDTA-P、Olsen-P 均没有显著的 相关性，与朱广伟等对长江中下游浅水湖泊的调查基本一致 ${ }^{[28]}$. 湿地上覆水磷素水平不仅和底泥中的磷 素含量有关, 还受到其他因素, 诸如动植物和微生物的作用、溶解氧、有机质等 ${ }^{[28-29]}$ 的影响, 是一个复杂 的多因素过程. 在所调查区域内, 湿地受到复杂的外界影响, 部分受纳大量农田灌溉排水, 部分仍旧受 工业生产的影响，也有一部分被当地农民用作养殖塘，这些客观因素的各异性也造成了泥-水含磷关系 的不确定性.

\section{2 室内模拟实验结果及分析}

2.2.1 静态实验上覆水 DRP 动态变化特征 三组实验上覆水 DRP 浓度表现出类似的变化趋势(图 2). 除 $0 \mathrm{mg} / \mathrm{L}$ 实验柱，其余上覆水 DRP 均呈现出随时间下降的总体趋势，曲线特点表现为初始阶段下降比较缓慢， 之后下降速度加快, 后期维持在较低水平的规律. 推其规律, 初始阶段, 由于底泥周围间隙水浓度较上覆水 低, 主要过程为上覆水中磷素沿浓度梯度向底泥间隙水迁移, 另据有关研究, 上覆水扰动程度越低则此阶 段持续时间越长 ${ }^{[30]}$; 底泥颗粒逐渐被较高磷浓度的溶液包围, 便开始大量吸附水中的磷素, 同时持续地形 成上覆水-间隙水磷素浓度梯度，在吸附作用以及浓度梯度双重作用下，上覆水 DRP 浓度下降速度加快. 笔 者认为, 大多关于底泥吸附动态特征的研究都基于人工强化手段使土-水相尽快达到平衡而鲜见本实验初 始阶段特征 ${ }^{[31-32]}$, 此次模拟实验恰是细化了此初始阶段, 并基本反映了枯水期湿地的上覆水磷素变化过程. 但实际条件下由于受到更多因素的干扰，比室内模拟复杂得多，有待于进一步研究.

2.2.2 稳流实验上覆水 DRP 动态变化特征 三组稳流水槽模拟实验上覆水 DRP 浓度变化特征见图 3. 总体 看，除 $0 \mathrm{mg} / \mathrm{L}$ 水槽，稳流实验中上覆水 DRP 大致表现出 U 型曲线特征，即初始阶段随时间下降、后期回 升的总体趋势, 这是由底泥磷素吸附与上覆水恒浓度磷素补给的动态过程决定的. 初始阶段底泥吸附磷 素的过程占明显优势, 上覆水 DRP 下降速度很快; 当底泥吸附速度与上覆水磷素补给达到动态平衡时, 
准 $\mathrm{U}$ 型曲线达到最低点, 即平衡点; 随后由于磷素补给速度超过底泥吸附速度, 上覆水磷素开始呈回升 趋势. 这与丰水期湿地的上覆水磷素变化规律类似. 丰水期由于水量较大, 会产生水平流, 如果含磷浓 度较高的污水持续地流过, 则开始阶段底泥会大量地吸附上覆水中的磷素, 然而随着时间推移, 泥-水界 面有可能达到该平衡点, 使湿地向周围环境输出的磷素含量偏高, 出现一次湿地的 “汇一源” 转换.
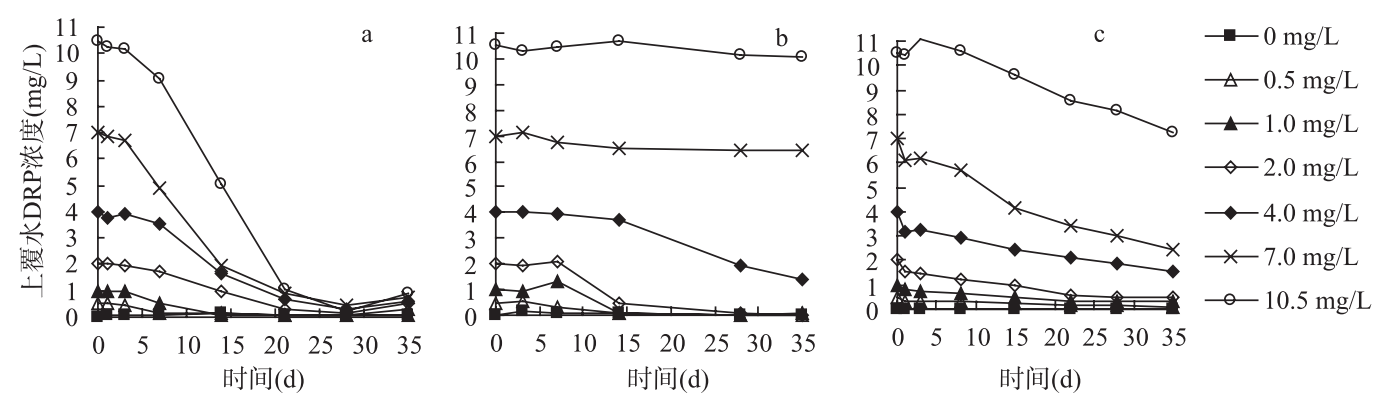

图 2 静态模拟实验上覆水 DRP 浓度变化

(a: 杭州西湖茅家埠泥样; b: 湖州长兴包漾河泥样; c: 湖州德清下渚湖泥样)

Fig.2 DRP dynamics of overlying water in static simulation experiments
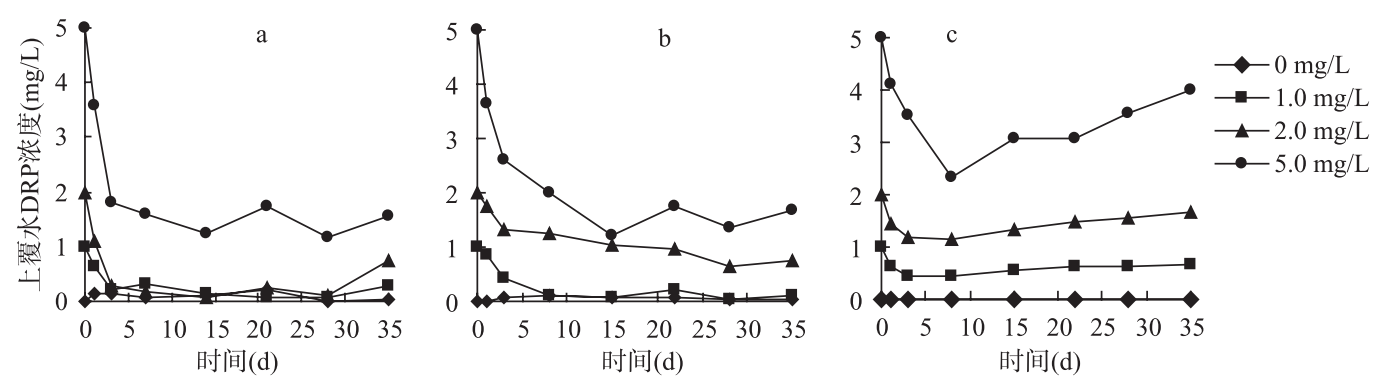

图 3 稳流模拟实验上覆水 DRP 动态变化

(a: 杭州西湖茅家埠泥样; b: 湖州长兴包漾河泥样; c: 湖州德清下渚湖泥样)

Fig.3 DRP dynamics of overlying water in steady-flow simulation experiments

2.2.3 底泥磷素吸附速率影响因素 无论在静态实验还是稳流实验中(图 2, 图 3), R2 对应的上覆水 DRP 变 化速率均明显大于 D1 和 R7. 静态实验中, $\mathrm{R} 2$ 处理的初始平稳阶段主要发生在前 7d, 之后第 8-21d DRP 迅速降低并趋近于 0 , 全部实验柱维持在 $1 \mathrm{mg} / \mathrm{L}$ 以下, 并出现少量波动; D 1 和 $\mathrm{R} 7$ 处理中 DRP 下降速率 明显低于西湖泥样, 只有 $0-2.0 \mathrm{mg} / \mathrm{L}$ 的实验柱在 $35 \mathrm{~d}$ 内降至趋近于 0 , 其余柱体内仍维持较高 DRP 浓度. 稳流实验中, R2 处理的 DRP 在第 $3 \mathrm{~d}$ 便降至平衡点, 并维持较低浓度; D1 和 R7 处理中 DRP 则分别在第 $15 \mathrm{~d} 、 8 \mathrm{~d}$ 才降至平衡浓度, 然而 R7 处理后期 DRP 开始回升时间较 D1 要早. 据此推断, 底泥磷素吸附速 率大小依次为 $\mathrm{R} 2>\mathrm{R} 7>\mathrm{D} 1$, 吸附能力大小依次为 $\mathrm{R} 2>\mathrm{D} 1>\mathrm{R} 7$. 由于实验室模拟免除了外界因素的干扰，降 低了生物、微生物的活性, 同时控制相对稳定的物理条件, 因此上覆水 DRP 浓度的降低主要发生在泥水界面, 其原理主要基于底泥的吸附作用, 并主要取决于底泥的物理化学参数 ${ }^{[33-34]}$. 磷素吸附容量大小 依次为 $\mathrm{R} 2>\mathrm{D} 1>\mathrm{R} 7$, 与模拟实验中效果一致; 有机质大小依次为 $\mathrm{R} 2>\mathrm{R} 7>\mathrm{D} 1$ (表 1), 与有关研究证明有机 质能够提高底泥磷素吸附速率相符 ${ }^{[32]}$.

\section{3 结语}

太湖流域南区 29 处典型湿地采样点的磷状况调查显示, 底泥含 TP $0.169-1.200 \mathrm{~g} / \mathrm{kg}$, Olsen-P 7.077- 
$67.080 \mathrm{mg} / \mathrm{kg}$, 最大磷素吸附容量 $Q_{\max }$ 为 $228.1-824.5 \mathrm{mg} / \mathrm{kg}$. 底泥中 TP、Olsen-P 与 NaOH+EDTA-P 具有 显著的线性相关关系，有机磷的积累可相应地提高底泥中 Olsen-P 的含量，是底泥磷素释放的潜在源. 分 析发现，区域内大多数湿地底泥物理吸附潜力已较弱. 区域内湿地上覆水含 TP $0.036-0.944 \mathrm{mg} / \mathrm{L}, \mathrm{DRP}$ 含量普遍较低. 一年中的 4-5 月份, 磷在调查区域湿地的上覆水中主要以颗粒态存在. 湿地上覆水 TP、 DRP 与底泥 TP、 NaOH+EDTA-P、Olsen-P 均没有显著的相关性, 说明了湿地上覆水磷素水平影响因素 的复杂性.

静态柱模拟实验中, 除 $0 \mathrm{mg} / \mathrm{L}$ 实验柱, 其余上覆水 DRP 均呈现出随时间衰减趋势, 并遵循初始阶段 衰减缓慢，之后衰减速度加快，后期维持在较低水平的规律. 稳流水槽模拟实验中，除 $0 \mathrm{mg} / \mathrm{L}$ 水槽，上覆 水 DRP 动态表现出准 $U$ 型曲线特征，这是由底泥磷素吸附与上覆水磷素补给的动态过程决定的. 丰水期 湿地如持续受纳含磷浓度较高的污水，则有可能达到准 U 型曲线平衡点，使湿地出现一次 “汇-源” 转换, 造成下游水体污染. 经验证, 底泥的磷素吸附能力在 Langmuir 吸附实验及室内模拟实验中表现一致, 并 且有机质的增多可提高底泥对磷的吸附速率. 实际环境条件下湿地底泥的磷素滞留/释放规律有待于做 进一步细致的研究.

致谢: 浙江大学环境与资源学院硕士研究生李慧以及 SRTP(大学生科研训练计划)学生董逸、卓淑琼协助 了本研究的实验室理化分析, 在此表示感谢.

\section{4 参考文献}

[1] 符建荣. 浙江省肥料面源污染现状与治理对策. 浙江农业科学, 2001: 323-324.

[2]尹澄清, 毛战坡. 用生态工程技术控制农村非点源水污染. 应用生态学报, 2002, 13(2): 229-232.

[3] Verhoeven JTA, Arheimer B, Yin Chengqing et al. Regional and global concerns over wetlands and water quality. Trends Ecol Evol, 2006, 21(2): 96-103.

[4] Groffman P, Baron J, Blett T et al. Ecological thresholds: The key to successful environmental management or an important concept with no practical application? Ecosystems, 2006, 9: 1-13.

[5] Elser JJ, Bracken MES, Cleland EE et al. Global analysis of nitrogen and phosphorus limitation of primary producers in freshwater, marine and terrestrial ecosystems. Ecolo Lett, 2007, 10: 1135-1142.

[6] Scheffer M, Carpenter S, Foley JA et al. Catastrophic shifts in ecosystems. Nature, 2001, 413(6856): 591-596.

[7] Carpenter SR. Eutrophication of aquatic ecosystems: Bistability and soil phosphorus. P Natl Acad Sci USA, 2005, 102(29): 10002-10005.

[8] Sondergaard M, Jensen JP, Jeppesen E. Role of sediment and internal loading of phosphorus in shallow lakes. Hydrobiologia, 2003, 506-509: 135-145.

[9] Jeppesen E, Sondergaard M, Jensen JP et al. Lake responses to reduced nutrient loading — an analysis of contemporary long-term data from 35 case studies. Freshwater Biol, 2005, 50: 1747-1771.

[10] Pant HK, Reddy KR. Potential internal loading of phosphorus in a wetland constructed in agricultural land. Water Res, 2003, 37: 965-972.

[11] House WA, Denison FH. Exchange of inorganic phosphate between river waters and bed-sediments. Environ Sci Technol, 2002, 36(20): 4295-4301.

[12] McDowell R, Sharpley A, Withers P. Indicator to predict the movement of phosphorus from soil to subsurface flow. Environ Sci Technol, 2002, 36: 1505-1509.

[13] May RM. Thresholds and breakpoints in ecosystems with a multiplicity of stable states. Nature, 1977, 269: 471-477.

[14] 赵慧霞, 吴绍洪, 姜鲁光. 生态阈值研究进展. 生态学报, 2007, 27(1): 338-345.

[15] 钱忠龙, 邵 慧, 李建强等. 浙北平原农业磷素面源污染的调查. 安徽农学通报, 2007, 13(7): 61-63.

[16] 鲍士旦. 土壤农化分析. 北京: 中国农业出版社, 2000: 30-34, 70-83.

[17] Cade-Menun BJ, Preston CM. A comparison of soil extraction procedures for ${ }^{31}$ P NMR spectroscopy. Soil Sci, 1996, 161(11): 770-785. 
[18] 国家环境保护总局《水和废水监测分析方法》编委会. 水和废水监测分析方法. 北京: 中国环境科学出版社, 2002: 243-258.

[19] Hooda PS, Moynagh M, Svoboda IF et al. Phosphorus loss in drainflow from intensively managed grassland soils. J Environ Qual, 1999, 28: 1235-1242.

[20] 章明奎, 周 翠, 方利平. 水稻土磷环境敏感临界值的研究. 农业环境科学学报, 2006, 25(1): 170-174.

[21] 张志剑, 王光火. 嘉兴地区水稻土磷素状况与环境效应评估. 科技通报, 1999, 15(5): 377-381.

[22] 尹澄清, 邵 霞, 王 星. 白洋淀水陆交错带土壤对磷氮截留容量的初步研究. 生态学杂志, 1999, 18(5): 7-11.

[23] Zhang Zhijian, Zhang Jianying, He Ruo et al. Phosphorus interception in floodwater of paddy field during the rice-growing season in Lake Taihu Basin. Environ Pollut, 2007, 145: 425-433.

[24] Sharpley AN, Chapra SC, Wodepohl R et al. Managing agriculture phosphorus protection of floodwaters: Issues and options. $J$ Environ Qual, 1994, 23: 437-451.

[25] Guppy CN, Menzies NW, Moody PW et al. Competitive sorption reactions between phosphorus and organic matter in soils: a review. Aust J Soil Res, 2005, 43: 189-202.

[26] Ahlgren J, Tranvik L, Gogoll A et al. Sediment depth attenuation of biogenic phosphorus compounds measured by ${ }^{31} \mathrm{P}$ NMR. Environ Sci Technol, 2005, 39(3): 867-872.

[27] Selig U, Hübener T, Michalik M. Dissolved and particulate phosphorus forms in a eutrophic shallow lake. Aquat Sci, 2002, 64 97-105.

[28] 朱广伟, 秦伯强, 高 光等. 长江中下游浅水湖泊沉积物中磷的形态及其与水相磷的关系. 环境科学学报, 2004, 24(3): 381-388.

[29] Spears BM, Carvalho L, Perkins R et al. Sediment phosphorus cycling in a large shallow lake: spatio-temporal variation in phosphorus pools and release. Hydrobiologia, 2007, 584: 37-48.

[30] Li Tao, Wang Dongsheng, Zhang Bin et al. Characterization of the phosphate adsorption and morphology of sediment particles under simulative disturbing conditions. J Hazard Mater, 2006, 137: 1624-1630.

[31] 邵宗臣, 赵美芝. 土壤中积累态磷活化动力学的研究: I. 有机质的影响. 土壤学报, 2002, 39(3): 318-325.

[32] Wang Shengrui, Jin Xiangcan, Zhao Haichao et al. Effect of organic matter on the sorption of dissolved organic and inorganic phosphorus in lake sediments. Colloid Surface A, 2007, 297: 154-162.

[33] 王圣瑞, 金相灿, 庞 燕. 湖泊沉积物对磷的吸附特征及其吸附热力学参数. 地理研究, 2006, 25(1): 19-26.

[34] 刘 敏, 侯立军, 许世远等. 长江河口潮滩表层沉积物对磷酸盐的吸附特征. 地理学报, 2002, 57(4): 397-406. 